Jurnal Kesehatan Karya Husada, Vol 9 No 1 Tahun 202

PISSN 2337649X/EISSN 2655-8874

Dechoni Rahmawati, Fatimah Dewi Anggraeni, Ristiana Eka Ariningtyas "Faktor-Faktor yang Berhubungan dengan Kesediaan Suami Sebagai Akseptor Metode Operasi Pria (MOP) di Sundi Kidul Argorejo Sedayu Bantul Yogyakarta" (hal 41-48)

Received

10 Desember 2020

Revisied

Acceptep

20 Februari 2021

16 Juni 2021

\title{
FAKTOR-FAKTOR YANG BERHUBUNGAN DENGAN KESEDIAAN SUAMI SEBAGAI AKSEPTOR METODE OPERASI PRIA (MOP) DI SUNDI KIDUL ARGOREJO SEDAYU BANTUL YOGYAKARTA
}

\author{
Dechoni Rahmawati ${ }^{1}$, Fatimah Dewi Anggraeni ${ }^{2}$ Ristiana Eka Ariningtyas $^{3}$ \\ ${ }^{1}$ Program Studi Kebidanan Universitas Jenderal Achmad Yani Yogyakarta \\ Email: dechoni.aris@gmail.com \\ 2 \\ Program Studi Kebidanan Universitas Jenderal Achmad Yani Yogyakarta \\ Email: dewianggraeni303@gmail.com \\ Program Studi Kebidanan Universitas Jenderal Achmad Yani Yogyakarta \\ Email: tyasarin1988@gmail.com
}

\begin{abstract}
ABSTRAK
Latar Belakang: Program Keluarga Berencana (KB) merupakan suatu program yang dicanangkan oleh pemerintah untuk meningkatkan kualitas hidup masyarakat di Indonesia. Salah satu metode kontrasepsi untuk pria adalah MOP (Metode Operasi Pria). Kebiasaan masyarakat yang menganggap bahwa masalah $\mathrm{KB}$ adalah wilayah perempuan dan pria tidak perlu terlibat juga menjadi salah satu penyebab kurangnya partisipasi pria dalam KB. Tujuan: Untuk mengidentifikasi faktor-faktor yang berhubungan dengan keikutsertaan suami dalam mengikuti program KB.Metodologi Penelitian: Jenis penelitian ini adalah observasional analitik dengan pendekatan cross-sectional. Lokasi penelitian ini di Sundi kidul, Argorejo, Sedayu, Bantul dengan sampel sebesar 30 responden dan teknik pengambilan sampel simple random sampling. Teknik uji statistik yang digunakan dalam penelitian ini adalah chi square.

Hasil Penelitian: Hasil penelitian menunjukkan bahwa pada variabel pendidikan didapatkan hasil suami yang memiliki latar belakang pendidikan yang tinggi akan memiliki kemungkinan 9 kali untuk bersedia menjadi akseptor KB MOP, pada variabel pekerjaan didapatkan hasil variabel pekerjaan tidak berhubungan dengan kesediaan suami. Kesimpulan: Berdasarkan hasil penelitian yang telah dilakukan menunjukkan bahwa factor pendidikan berpengaruh terhadap kesediaan suami menjadi akseptor KB MOP.
\end{abstract}

Kata Kunci: Kontrasepsi MOP, Suami. 
Jurnal Kesehatan Karya Husada, Vol 9 No 1 Tahun 202

PISSN 2337649X/EISSN 2655-8874

Dechoni Rahmawati, Fatimah Dewi Anggraeni, Ristiana Eka Ariningtyas "Faktor-Faktor yang Berhubungan dengan Kesediaan Suami Sebagai Akseptor Metode Operasi Pria (MOP) di Sundi Kidul Argorejo Sedayu Bantul Yogyakarta" (hal 4l-48)

\section{PENDAHULUAN}

Program Keluarga Berencana (KB) merupakan suatu program yang dicanangkan oleh pemerintah untuk meningkatkan kualitas hidup masyarakat di Indonesia, hal tersebut termaktub dalam Undang-Undang Republik Indonesia Nomor 52 Tahun 2009 Tentang Perkembangan Kependudukan dan Pembangunan Keluarga. Hasil Sensus Penduduk pada tahun 2015, Indonesia berada pada peringkat ke empat sebagai negara dengan jumlah penduduk terbesar di dunia yakni sekitar 237,6 juta jiwa (Indonesia Demographic and Health Survey (IDHS), 2016). Sebagai negara berkembang, Indonesia membutuhkan upaya untuk mengendalikan laju pertumbuhan penduduk selama satu dekade terakhir ini. Terdapat berbagai upaya yang dapat ditempuh oleh pemerintah dalam mengendalikan laju pertumbuhan penduduk. Salah satu upaya yang dapat dilakukan adalah dengan program KB.

Undang-Undang Republik Indonesia Nomor 52 Tahun 2014 tentang Perkembangan Kependudukan dan Pembangunan Keluarga menyatakan bahwa program KB sebagai salah satu upaya untuk mewujudkan keluarga sehat dan berkualitas. Pengaturan kehamilan dalam Program KB dilakukan dengan alat kontrasepsi. Alat kontrasepsi sendiri memiliki berbagai jenis, diantaranya adalah Intra Uterine Device (IUD), Metode Operasi Wanita (MOW), Metode Operasi Pria (MOP), Implan, Suntik, Pil dan Kondom. Salah satu metode kontrasepsi untuk pria adalah MOP (Metode Operasi Pria) atau yang sering disebut dengan vasektomi. Menurut Rayala dan Viera (2016) merupakan pilihan kontrasepsi permanen pada pria yang aman, terpercaya dengan biaya yang relatif terjangkau serta efektif. Berdasarkan Survei Demografi dan Kesehatan Indonesia (SDKI, 2018) yang tercantum dalam Pusat Data dan Informasi Kementerian Kesehatan Republik Indonesia, pada tahun 2012 peserta KB di Indonesia sebesar 61,4\%, dan tahun 2017 sebesar $61,9 \%$. Akan tetapi peserta program KB untuk para laki-laki masih rendah sejumlah 21.374 peserta dengan presentase sebesar $\quad 0,25 \%$ untuk vasektomi (www.bkkbn.go.id). 
Jurnal Kesehatan Karya Husada, Vol 9 No 1 Tahun 202

PISSN 2337649X/EISSN 2655-8874

Dechoni Rahmawati, Fatimah Dewi Anggraeni, Ristiana Eka Ariningtyas "Faktor-Faktor yang Berhubungan dengan Kesediaan Suami Sebagai Akseptor Metode Operasi Pria (MOP) di Sundi Kidul Argorejo Sedayu Bantul Yogyakarta" (hal 4l-48)

\section{BAHAN DAN CARA \\ PENELITIAN}

Penelitian ini merupakan penelitian jenis analitik observasional dengan pendekatan cross-sectional Dalam penelitian ini variebel terikat yaitu kesediaan suami dan variabel bebas yaitu Pengetahuan, Pekerjaan, Fasilitas Kesehatan, Kualitas Layanan, Nilai budaya, pendidikan, pekerjaan diambil secara bersamaan dalam satu waktu.

Penelitian ini dilakukan dengan cara memilih responden yang sesuai dengan kriteria yang telah ditetapkan kemudian akseptor diberikan beberapa pertanyaan tentang KB MOP dan kemudian hasil dari jawaban responden diolah dan dideskripsikan terkait studi deskriptif faktor yang mempengaruhi kesediaan suami sebagai akseptor KB MOP di Sundi Kidul, Argorejo, Sedayu, Bantul, Yogyakarta.

Tabel 4.1 Deskripsi Karakteristik Responden

\begin{tabular}{|c|c|c|c|}
\hline No & $\begin{array}{c}\text { Karakteristik } \\
\text { Responden }\end{array}$ & Frekuensi & Persentase \\
\hline 1 & Usia (Tahun) & & \\
\hline & $21-30$ & 1 & $3.3 \%$ \\
\hline & $31-40$ & 18 & $60 \%$ \\
\hline & $41-50$ & 6 & $20 \%$ \\
\hline & 50 & 5 & $16.7 \%$ \\
\hline 2 & Penghasilan & & \\
\hline & Tinggi > UMR & 16 & $53.3 \%$ \\
\hline & $\overline{\text { Rendah }<\text { UMR }}$ & 14 & $46.7 \%$ \\
\hline
\end{tabular}

\begin{tabular}{|c|c|c|c|}
\hline 3 & Pendidikan & & \\
\hline & Rendah & 12 & $40 \%$ \\
\hline & Tinggi & 18 & $60 \%$ \\
\hline 4 & Pekerjaan & & \\
\hline & Bekerja & 27 & $90 \%$ \\
\hline & Tidak Bekerja & 3 & $10 \%$ \\
\hline 5 & Kesediaan & & \\
\hline & Tidak Bersedia & 20 & $66.7 \%$ \\
\hline & Bersedia & 10 & $33.3 \%$ \\
\hline
\end{tabular}

Berdasarkan Tabel 4.1 diketahui bahwa sebagian besar responden berusia antara 31- 40 tahun, yaitu sebanyak 18 $(60 \%)$ responden, usia 41 - 50 tahun sebanyak 6 (20\%), usia > 50 tahun sebanyak $5(16,7 \%)$ dan usia 21 - 30 tahun hanya $1(3,3 \%)$ responden. Penghasilan responden paling banyak berpenghasilan $\geq$ UMR yaitu sebanyak $16 \quad(53,3 \%)$, dan responden yang berpenghasilan <UMR sebanyak $14(46,7 \%)$ responden. Pada variable pendidikan, kategori rendah sebanyak 12 (40\%) responden, dan kategori tinggi sebanyak 18 (60\%) responden. Pada variabel pekerjaan, responden paling banyak yaitu bekerja sebanyak 27 orang (90\%) dan yang tidak bekerja sebanyak 3 orang (10\%). Pada variabel kesediaan, sebagian besar pada kategori tidak bersedia sebesar $66,7 \%$ (20 orang).

\section{HASIL}

\section{Variabel Pendidikan Terhadap Kesediaan Suami Melakukan MOP}


Jurnal Kesehatan Karya Husada, Vol 9 No 1 Tahun 202

PISSN 2337649X/EISSN 2655-8874

Dechoni Rahmawati, Fatimah Dewi Anggraeni, Ristiana Eka Ariningtyas "Faktor-Faktor yang Berhubungan dengan Kesediaan Suami Sebagai Akseptor Metode Operasi Pria (MOP) di Sundi Kidul Argorejo Sedayu Bantul Yogyakarta" (hal 4l-48)

Tabel 4.2 Hasil uji variabel pendidikan terhadap kesediaan suami melakukan MOP

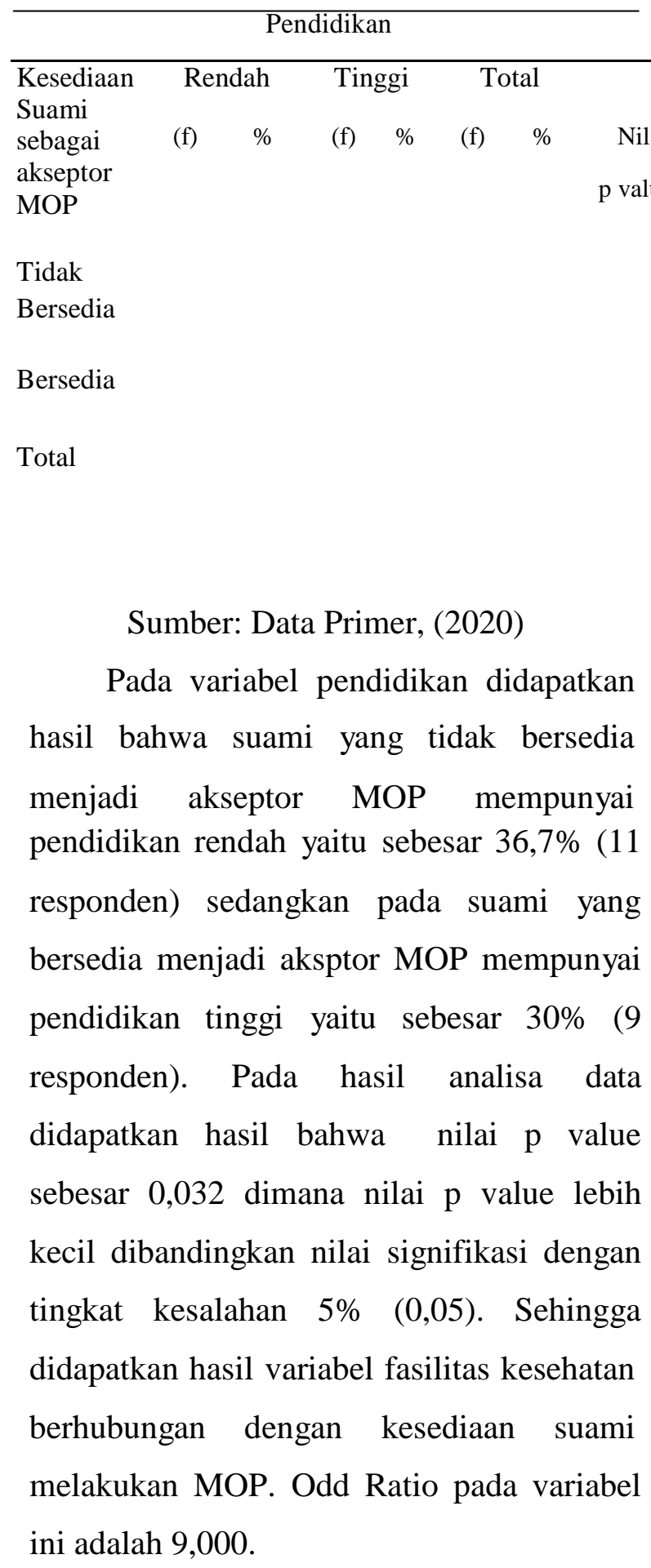

\section{Variabel Pekerjaan Terhadap} Kesediaan Suami Melakukan MOP Tabel 4.3 Hasil uji variabel pendidikan terhadap kesediaan suami melakukan MOP

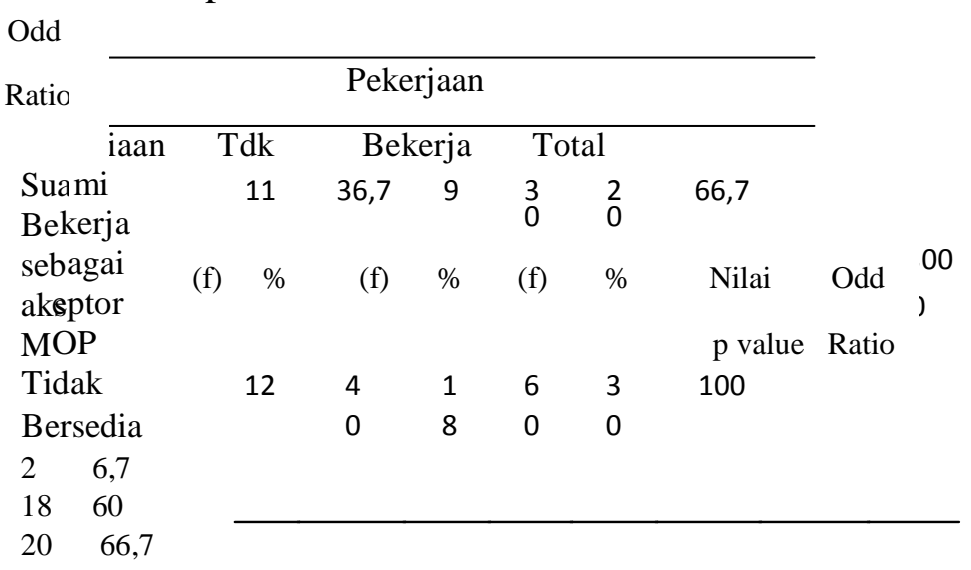

$\begin{array}{lllllllll}\text { Bersedia } & 1 & 3,3 & 9 & 30 & 10 & 33,3 & 1,000 & 1,000\end{array}$

$\begin{array}{lllllll}\text { Total } & 3 & 10 & 27 & 90 & 30 & 100\end{array}$

Sumber: Data Primer, (2020)

Pada variabel pekerjaan didapatkan hasil bahwa suami yang tidak bersedia menjadi akseptor MOP sebagian besar berada pada status bekerja yaitu sebesar 60\% (18 responden) sedangkan pada suami yang bersedia menjadi aksptor MOP sebagian besar berada pada status bekerja yaitu sebesar 30\% (9 responden). Pada hasil analisa data didapatkan hasil bahwa nilai $\mathrm{p}$ value sebesar 1,000 dimana nilai $\mathrm{p}$ value lebih besar dibandingkan nilai signifikasi dengan tingkat kesalahan $5 \% \quad(0,05)$. Sehingga didapatkan hasil variabel pekerjaan 
Jurnal Kesehatan Karya Husada, Vol 9 No 1 Tahun 202

PISSN 2337649X/EISSN 2655-8874

Dechoni Rahmawati, Fatimah Dewi Anggraeni, Ristiana Eka Ariningtyas "Faktor-Faktor yang Berhubungan dengan Kesediaan Suami Sebagai Akseptor Metode Operasi Pria (MOP) di Sundi Kidul Argorejo Sedayu Bantul Yogyakarta" (hal 41-48)

tidak berhubungan dengan kesediaan suami melakukan MOP. Odd Ratio pada variabel ini adalah 1,000 .

\section{PEMBAHASAN}

\section{Hubungan Faktor Pendidikan Dengan Kesediaan Suami Menjadi Akseptor KB MOP}

Pada variabel Pendidikan didapatkan hasil bahwa suami yang tidak bersedia menjadi akseptor MOP sebagian besar mempunyai pendidikan rendah yaitu sebesar 36,7\% (11 responden) sedangkan pada suami yang bersedia menjadi akseptor MOP mempunyai pendidikan tinggi yaitu sebesar 30\% (9 responden). Pada hasil analisa data didapatkan hasil bahwa nilai $\mathrm{p}$ value sebesar 0,032 dimana nilai $\mathrm{p}$ value lebih kecil dibandingkan nilai signifikasi dengan tingkat kesalahan $5 \%(0,05)$. Sehingga didapatkan hasil variabel fasilitas kesehatan berhubungan dengan kesediaan suami melakukan MOP. Nilai odd ratio pada variabel ini adalah 9,000.

Pada penelitian ini, didapatkan nilai Odd Ratio dalam variabel pendidikan menunjukan nilai 9,000 yang artinya suami yang memiliki latar belakang pendidikan yang tinggi akan memiliki kemungkinan 9 kali untuk bersedia menjadi akseptor KB
MOP dibandingkan yang memiliki latar belakang pendidikan yang rendah.

Orang yang berpendidikan tinggi akan memberikan respon yang lebih rasional terhadap informasi yang datang dari dan berfikir sejauh mana keuntungan yang mungkin akan mereka peroleh dari gagasan tersebut. Selain itu, pengalaman yang diperoleh dari lingkungan kehidupan dalam proses perkembangannya juga akan mempengaruhi tingkat pengetahuan seseorang (Sukmadinata, 2015)

Dengan pendidikan yang tinggi diharapkan seseorang dapat menerima informasi baru yang dianggap penting sehingga akan meningkatkan pengetahuan dan dari pengetahuan tersebut seseorang akan memiliki sikap yang baik. Sikap bidan dalam menerima informasi baru khususnya konseling awal kontrasepsi akan dimulai dari menerima, merespon, menghargai dan bertanggungjawab (Notoatmodjo, 2007).

\section{Hubungan Faktor Pekerjaan Dengan}

Kesediaan Suami Menjadi Akseptor KB MOP

Pada variabel pekerjaan didapatkan hasil bahwa suami yang tidak bersedia menjadi akseptor MOP sebagian besar berada pada status bekerja yaitu sebesar 
Jurnal Kesehatan Karya Husada, Vol 9 No 1 Tahun 202

PISSN 2337649X/EISSN 2655-8874

Dechoni Rahmawati, Fatimah Dewi Anggraeni, Ristiana Eka Ariningtyas "Faktor-Faktor yang Berhubungan dengan Kesediaan Suami Sebagai Akseptor Metode Operasi Pria (MOP) di Sundi Kidul Argorejo Sedayu Bantul Yogyakarta" (hal 4l-48)

60\% (18 responden) sedangkan pada suami yang bersedia menjadi aksptor MOP sebagian besar berada pada status bekerja yaitu sebesar $30 \%$ (9 responden). Pada hasil analisa data didapatkan hasil bahwa nilai $\mathrm{p}$ value sebesar 1,000 dimana nilai $\mathrm{p}$ value lebih besar dibandingkan nilai signifikasi dengan tingkat kesalahan $5 \% \quad(0,05)$. Sehingga didapatkan hasil variabel pekerjaan tidak berhubungan dengan kesediaan suami melakukan MOP. Odd Ratio pada variabel ini adalah 1,000 .

Faktor pendorong penting yang menyebabkan manusia bekerja adalah adanya kebutuhan yang harus dipenuhi. Aktivitas dalam kerja mengandung unsur suatu kegiatan sosial, menghasilkan sesuatu, dan pada akhirnya bertujuan untuk memenuhi kebutuhannya. Namun demikian di balik tujuan yang tidak langsung tersebut orang bekerja untuk mendapatkan imbalan yang berupa upah atau gaji dari hasil kerjanya (As'ad, 2012)

\section{KEPUSTAKAAN}

Addah, A.O., et.al. (2014). To Determine The Knowledge and Attitudes on Modern Contraceptive Use Amongst Antenatal Attendees At The Niger Delta University Teaching Hospital, Okolobiri, South-South Nigeria. IOSR Journal of Dental and Medical
Sciences (IOSR-JDMS). Volume 13, Issue 4. Ver.VI (Apr.2014), pp 01-07.

Agarwal, Koki, (2011), Family Planning and Reproductive Health, Paper Council on Foreign Relations, 1-14.

Atikah Proverawati, dkk. (2012). Panduan Memilih Kontrasepsi. Yogyakarta: Nuha Medika.

BKKBN. (2018). Badan Pusat Statistik Kementerian Kesehatan, Survei Demografi dan Kesehatan Indonesia.

Bernadus J D, Madianung A, Masi G.

2013. Faktor-Faktor Yang Berhubungan Dengan Pemilihan Alat Kontrasepsi Dalam Rahim (Akdr) Bagi Akseptor Kb Di Puskesmas Jailolo. Jurnal e-NERS (eNS), Volume 1, Nomor 1, Maret 2013, hlm. 1- 10

Budisantoso, (2011). Partisipasi Pria dalam Keluarga Berencana di Kecamatan Jetis Kabupaten Bantul. Jurnal Promosi Kesehatan Indonesia Vol.4/No.2/Agustus 2011.

E \& R Study. (2012). Factors Affecting Vasectomy Acceptability in the Kigoma Region of Tanzania. ACQUIRE Evaluation and Research Studies.

Fitri, M., Wantouw, B., dan Tendean, L. (2016). Pengaruh Vasektomi terhadap Fungsi Seksualitas Pria. Jurnal e-Biomedik (eBM), Volume 1, Nomor 1, Maret 2016. 
Jurnal Kesehatan Karya Husada, Vol 9 No 1 Tahun 202

PISSN 2337649X/EISSN 2655-8874

Dechoni Rahmawati, Fatimah Dewi Anggraeni, Ristiana Eka Ariningtyas "Faktor-Faktor yang Berhubungan dengan Kesediaan Suami Sebagai Akseptor Metode Operasi Pria (MOP) di Sundi Kidul Argorejo Sedayu Bantul Yogyakarta" (hal 4l-48)

Hanum Marimbi. (2011). Sosiologi dan Antropologi Kesehatan. Yogyakarta: Nuha Medika.

Hartanto, Hanafi. (2016). Keluarga Berencana dan Kontrasepsi, Pustaka Sinar Harapan, Jakarta.

Heejung, S.K., David K.S., and Shelley, E.T. (2012). Culture and Sociap Support. American Psychologist, September 2012.

Indonesia Demographic and Health Survey (IDHS). (2016). Statistics Indonesia National Population and Family Planning Board Ministry of Health. MEASURE DHS: ICF International

Jones, R.K. (2011). Beyond Birth Control: The Overlooked Benefits of Oral Contraceptive Pills. New York: Guttmacher Institute, November 2011.

Kriebs JM \& Gegor CL. Buku saku Asuhan Kebidanan Varney (Edisi Kedua). Jakarta: EGC, 2011.

Michael Jobu Esabella. (2012). Use of Contraceptives Methods Among Women In Stable Marital Relations Attending Health Facilities In Kahama District, Shinyanga Region, Tanzania. Muhimbili University of Health and Allied Sciences: Master of Public Health Dissertation.

Murti, Bhisma. (2013). Desain dan ukuran sampel untuk penelitian kuantitatif dan kualitatif di bidang kesehatan. Cetakan ketiga. Yogyakarta: Gajah Mada University Press.
Nanlohy, S. 2017. Determinan Kejadian Unmet Need Keluarga Berencana di Kecamatan Penakkukang Kota Makassar. Skripsi. Fakultas Kesehatan Masyarakat Universitas Hasanuddin

Notoatmodjo, S. 2014. Ilmu Perilaku Kesehatan. Jakarta: Rineka Cipta

Novianti, S., dan Gustaman, R.A. (2014). Faktor Persepsi dan Dukungan Istri yang Berhubungan dengan Partisipasi KB Pria. Jurnal Kesehatan Komunitas Indonesia, Vol. 10, No. 2, September 2014.

Nugroho, T., dan Utama, B.I. (2014). Masalah Kesehatan Reproduksi Wanita. Yogyakarta: Nuha Medika.

Prawirohardjo, Sarwono. (2012). Ilmu Kebidanan. Jakarta: YBP-SP

Priyoto. (2014). Teori Sikap dan Perilaku Dalam Kesehatan. Yogyakarta: Nuha Medika.

Rayala, B.Z., and Viera, A.J. (2013). Common Questions About Vasectomy. American Family Physician. Volume 88, Number 11, December 1, 2016.

Sri Madya Bhakti Ekarini. (2018). Analisis Faktor-Faktor Yang Berpengaruh Terhadap Partisipasi Pria Dalam Keluarga Berencana Di Kecamatan Selo Kabupaten Boyolali, Tesis. Universitas Diponegoro: Program Pascasarjana.

Sutinah. (2013). Partisipasi laki-laki dalam program Keluarga Berencana di era masyarakat postmodern. Masyarakat, 
Jurnal Kesehatan Karya Husada, Vol 9 No 1 Tahun 202

PISSN 2337649X/EISSN 2655-8874

Dechoni Rahmawati, Fatimah Dewi Anggraeni, Ristiana Eka Ariningtyas "Faktor-Faktor yang Berhubungan dengan Kesediaan Suami Sebagai Akseptor Metode Operasi Pria (MOP) di Sundi Kidul Argorejo Sedayu Bantul Yogyakarta" (hal 4l-48)

Kebudayaan dan Politik. Vol.30, No.

3, tahun 2017, Hal. 289-299.

Utami, V.W. (2014). Faktor-faktor yang Mempengaruhi Penggunaan Vasektomi di Kota Bandar Lampung. JURNAL KESEHATAN HOLISTIK Vol. 8, No. 3, Juli 2014 : 115-119.

Undang - Undang Republik Indonesia Nomor 52 Tahun 2014 Tentang Perkembangan Kependudukan dan Pembangunan Keluarga.

Widowati, N.,Pitoyo, A.J., dan Hadna, A.H (2013). Pencapaian Program KB Pria: Vasektomi di Kecamatan Dlingo dan Sewon, Kabupaten Bantul. Jurnal Manajemen dan Pelayanan Farmasi. Volume 3 Nomor 2 - Juni 2013.

Winner, Brooke, et al (2012). Effectiveness of Long-ActingReversible

Contraception. The New England Journal of Medicine. May 24, 2012. 